\title{
Relativism, Objectivity, and Law
}

Contingencies of Value: Alternative Perspectives for Critical Theory. By Barbara Herrnstein Smith.* Cambridge: Harvard University Press, 1988. Pp. 229. $\$ 22.50$.

\section{Robin West†}

Barbara Herrnstein Smith's primary topic in her recent book, Contingencies of Value, ${ }^{1}$ is the act of evaluation - what it is we are doing when we evaluate an art work, a culture, a belief, a practice-and her secondary topic is the meaning of value-what value must mean, given the nature of our practices of evaluation. The book puts forward two major claims. First, Smith argues that all objectivist theories of value-by which she means those theories which ascribe objective value to the thing being valued-in both aesthetics and moral philosophy, and including critical theory as well as traditional objectivist accounts, are irretrievably authoritarian. Second, the book articulates and defends a particular relativist theory of value. All value, Smith argues, whether of a thing, belief, culture, tradition, art work, or anything else, is inevitably contingent on some "economy" of interests, beliefs, motives, prejudices, etc.-whether that of the individual, the society, or the species. Claims that an object, practice, moral system, culture, or tradition have value, then, can and should be understood to mean that the individual (culture, tribe, or species) offering that assessment has some set of interests, needs, or economies for which the thing valued has some positive use. Furthermore, the purportedly objective value many of us ascribe to high culture, canonical literature, Judeo-Christian moral principles, liberal democratic political principles, or whatever else we think of as having great or even absolute value, can be readily seen to be contingent on these private, cultural, or personal economies. The resistance, then, of the guardians of culture, morality, and political truth to relativist accounts of value which stress the contingency of what we value stems from a need, interest, or desire of the dominant group to maintain its authoritative power to define the good and the true, and to do so by masking the contingency of those values on the economies of the dominant.

\footnotetext{
* Braxton Craven Professor of Comparative Literature and English, Duke University.

+ Professor of Law, University of Maryland Law School; Visiting Research Fellow, Institute for Philosophy and Public Policy, College Park, Maryland.

1. B. Smith, Contingencies of Value (1988) [hereinafter cited by page number only].
} 
Smith's attack on objectivism proceeds by way of close readings of major theorists of the objectivist tradition in aesthetics and in moral philosophy, including such diverse objectivists as Kant, ${ }^{2}$ Hume, ${ }^{3}$ Alisdair McIntyre, ${ }^{4}$ and the various thinkers within the modern and postmodern "critical theory" movement." All of these objectivists, Smith shows, attempt to illustrate the coherence of the concept of objective and in each case, although there are differences between them, their core arguments turn on similar sorts of assertions. All eventually fall back on an argument of this form: One sort of literature is of greater value than another, one sort of culture is of greater value than another, or one way of life is of greater value than another, because "man" is constituted in such a way as to render the preferred literature, culture, or way of life more valuable to him. Those who do not appreciate the greater value are simply deficient human beings. Objectivism in all of its variant forms, then, rests on hidden or not so hidden claims about our true human nature or human potential. Such claims have the double function of inscribing the imprimatur of the "norm" and the "ideal" on the dominant group, and the imprimatur of the deviant, the deficient, or the misguided on the outsider-on those for whom the "objectively" higher or better way of life is ill-suited. Objectivism in all of its forms-aesthetic, literary, political, and moral-is thus one way among others that the stronger members in a society maintain their position. Objectivism masks both the necessity of their power for the general acceptance of their claims of truth, and the contingency of those claims on their particular interests, needs, and desires. Objectivism transforms social hierarchy and inequalities of power into descriptions of the external world. ${ }^{6}$

Smith's own relativist account of value draws heavily and fruitfully upon a revised version of the utilitarian moral tradition in philosophy, and a re-working and expansion of what has come to be called normative economics in the social sciences. All value, Smith argues, can be and should be understood as contingent on the needs, interests, projects, or desires-in short, the economies-of an individual or group. ${ }^{7}$ It is those economies, and not any intrinsic property of the thing itself, which accounts for the value of things, cultures, etc., in the external world. Where Smith parts company from the classical utilitarian tradition is in her refusal to reduce utility to any particular subjective interest, such as the interest in maximizing pleasure. Individual and social projects, Smith argues, are too varied and unpredictable to reduce to a single calculus. We

\footnotetext{
2. Pp. 64-72.

3. Pp. 55-64.

4. Pp. 85-94.

5. Pp. 173-79.

6. Pp. 54-84.

7. Pp. 125-49.
} 
may, from time to time, and for any number of reasons, have projects or interests which cannot be so neatly cabined. ${ }^{8}$ Where she departs from normative economics is in her refusal to limit those interests, desires, or preferences which constitute our economies to those which are quantifiable. Rather, our interests, desires, and needs often take forms which cannot be reduced to any quantifiable or calculable variable. ${ }^{9}$ Thus, while the concept of utility has great meaning for Smith, as it does for utilitarians and economists (it is that on which value is contingent), it cannot, for Smith, accomplish what it does for utilitarian economists: It cannot reduce questions of value to calculable questions of fact. Utility, for Smith, provides an alternative and presumably truer (in some sense) vocabulary within which to formulate and answer questions of value: what we value, what we should value, and why.

Smith then defends this form of what might be called "economic relativism" against three of the most familiar objections often raised against it: (1) that relativism is self-refuting (because it puts forward claims which it holds to be universally true); (2) that relativism, at least in the moral realm, commits the actor to a quietistic acceptance of her own social order; and (3) that relativism implies an unacceptably "egalitarian" acceptance of all competing social and individual moral beliefs and social systems.

Against the first, Smith argues that the objection itself is questionbegging: It assumes an objectivist account of truth, and then accuses relativism of putting forward "true" statements as understood in the objectivist sense, hence violating its own fundamental skepticism about the viability of such statements. In fact, Smith argues, the relativist does not need to engage in'such self-contradiction. The relativist does indeed assert statements the relativist believes to be true, but "true" here must be understood, as everywhere, as relatively true: true, relative to the interests, projects, or economies of the individual or community putting forward the claims. So modified, relativism as a theory becomes an example of its foundational claims, rather than an unintended refutation of them. ${ }^{10}$

Neither, Smith argues, is the relativist committed to a quietistic acceptance of the presently constituted projects or economies of the society in which she finds herself situated. Relativists can and do politic, argue, fight, and on occasion kill for their convictions, just as do objectivists. Relativists are by virtue of their relativism no less critical, and no more barred from critical and evaluative claims, than are objectivists. No one really doubts that relativists behave this way. Objectivists interpret such behavior, however, in a way that they believe counts against relativism itself: The relativist's critical behavior shows that the relativist can't possi-

\footnotetext{
8. Pp. 144-49.

). Pp. 134-44.

10. Pp. 150-66.
} 
bly live according to her relativist premises. Far from constituting such proof, however, Smith argues that the objectivist rejoinder simply indicates that the objectivist can't conceive of value in other than axiological terms. The relativist's denunciation of others' beliefs, moral systems, political forms of government, or aesthetic tastes will, undoubtedly, take a different form than the objectivist's: The objectivist will denounce the errant views of others on the basis of Truth or the Good, while the relativist will denounce the views of others on the basis of the competing interests and projects of the relativist and her antagonist. In putting forward such a denunciation, the relativist will explain, cajole, argue, and attempt whatever will "turn the trick." All the relativist will not do is assert what is not the case: that her own assessments of value are grounded in truth, or reality, or the external nature of things, rather than in her own (or her society's own, or her subgroup's own) personal, private, or cultural economies. ${ }^{11}$

Lastly, and similarly, the relativist is not committed by virtue of her relativism to an egalitarian acceptance of the conflicting moral and political systems of other cultures, although she will be disinclined to denounce them, as might the objectivist, on the grounds of their inherent error. Again, the objectivist's suspicion that the relativist cannot consistently denounce contrasting cultural systems, or his insistence that the relativist's manifest willingness to engage in such denunciatory activity simply reveals the inability of someone to actually "live that way," again illustrates not the impossibility of relativist criticism, but rather, the inability of the objectivist to conceive of value in other than axiological terms. The relativist will indeed willingly rank some cultural system, moral beliefs, etc., as better than others. Yet, she will do so not on the basis of their intrinsic value, but on the basis of their contingent value: Some cultures are more utile, more useful, more economic than are others. ${ }^{12}$

In this review, I will focus on what I take to be the most valuable attribute of Smith's treatments of objectivism and relativism to legal scholars, and that is her focus on the political, rather than the logical, objections, to each of these two competing conceptions of value. Both objectivism and relativism are obviously vulnerable to a bewildering set of forceful objections and each has generated a broad critical literature from the opposing camp. Smith has focused on the distinctively political objections that each has raised about the other: Objectivism, according to modern relativists, is politically objectionable in its tendency to over-credit the interests or views of the dominant class in the name of false universals. On the other hand, relativism, according to modern objectivists, is politically objectionable in its tendency toward "quietism": its pacific accept- 
ance of whatever social structures have produced the interests, projects, goals, and "personal economies" on which all value is contingent. Whatever the merits of Smith's attack on objectivism and defense of relativism, her book serves a valuable purpose by isolating and highlighting these distinctively political and pragmatic sorts of objections to both traditions.

I will make three major claims. First, both Smith's attack on objectivism and her defense of relativism rest strongly on the claim, perhaps correct, that objectivist rejections of relativism depend on a caricatured, highly stylized, and utterly false depiction of relativism. ${ }^{13}$ Relativists, according to the objectivists' caricature, are nihilistic, sociopathic monsters, unable to engage in serious evaluative work of any sort, both blind and wedded to their own cultural biases while at the same time blandly egalitarian in their permissive attitudes toward the differing commitments of others. It is against this caricature that objectivism appears not only attractive, but inevitable - as the only possible way to think about moral issues that avoids the quietism, egalitarianism, and nihilism of relativist modes of thinking. I will argue in this review that although there is something to Smith's complaint-objectivist depictions of relativism often do border on the hysterical-Smith's own defense of relativism suffers from an equally caricatured account of objectivism. According to this caricature, objectivists are moral and cultural authoritarians, unable to appreciate the value of diversity, wedded to their own vision of the Absolute Truth and the Categorical Right and Good, and fanatical in their urge to reify their own interests into features of the external world. Against this caricature, relativism looks attractive and indeed inevitable - the only possible way to think about moral (or aesthetic) value that avoids the authoritarianism, dogmatism, and in the extreme, the terrorism of objectivist modes of thinking. If we take seriously the caricature of relativism with which Smith charges objectivist moral theory, and take equally seriously the caricature of objectivism which runs through Smith's own arguments, then the debate between relativism and objectivism looks a lot like a debate between, say, Ted Bundy and the Ayatollah Khomeini: a relativist, nihilist Bundy, incapable of distinguishing his own lethal interests from moral truth, and an authoritarian and dictatorial Ayatollah Khomeini, incapable of disengaging his perception of Moral Truth from his claim to and need for power.

My first aim in this review is simply to argue against both caricatures. There are considerably more benign, more appealing forms of both objectivism and relativism than those either exposed or assumed by Smith. Contrary to Smith's caricatured conception of objectivism, there are forms of objectivist thought that avoid the authoritarianism with which she sad-

13. Pp. $150-56$. 
dles it; contrary to the caricatured forms of relativism asserted by objectivists, there are indeed forms of relativism that avoid quietism and false egalitarianism.

I do not think, though, that the particular relativist program put forward by Smith - which I will call "economic relativism" - successfully avoids either objection. Thus, my second goal is to argue that although relativism need not be overly egalitarian or quietistic, economic relativism of the sort defended by Smith may well be, and Smith's book might inadvertently prove it.

My third goal in this review is to offer an explanation of what might appear somewhat anomalous-at least to lawyers-about the appeal of Smith's work, and to do so not in terms of the objective merit of the arguments themselves, but in terms of the "economies" of the various audiences who might take an interest in her project. My prediction is that Smith's account of relativism and critique of objectivist evaluation will be least persuasive to that audience at which it appears to be explicitly targeted: the legions of professional moral philosophers and aestheticians for whom relativism is a flatly untenable conception of the nature of normative judgment. For professional philosophers convinced of the rightness of objectivity in evaluation, this book will confirm, rather than shake that commitment. From an objectivist standpoint, the defense of relativism Smith presents is inadequate to meet the charges of self-refutation, quietism, and egalitarianism; indeed, the book well illustrates at least the last two objections. The attack on objectivism is similarly long on assertion and short on argumentation. Nowhere is it argued that there is anything fallacious or wrongheaded about the particular objectivist strategy targeted by Smith: The construction of an ideal of human nature against which various cultural constructs, such as art, morality or politics, might be objectively evaluated. Without such an argument, I suspect, this book will not convince. One way to put the problem in terms conducive to Smith's frame of reference might be this: Most professional "axiological" traditional moral philosophers and aestheticians simply do not feel the "tug" or appeal of relativism, and do not experience the offensive intolerance of objectivist ways of thinking which have clearly motivated the writing of this book. To the group Smith apparently most wants to address-traditional objectivist moral philosophers and aestheticians-the relativism she defends is little more than a sophomoric strategy indulged by undergraduates in search of easy answers and anti-authoritarian postures. For reasons which Smith to her credit acknowledges, ${ }^{14}$ this book will do little to correct that impression and may go some way toward confirming it.

The book's central claims will, however, be far more persuasive to an 
audience Smith does not explicitly address but which will nevertheless find the book of great interest; namely legal scholars. Legal scholars do feel the tug of relativism, and powerfully; they have experienced (and continue to) the offensive intolerance of objectivist ways of evaluating cultural practices and constructs. For the legal audience, many of the arguments Smith puts forward against objectivism and in defense of relativism will seem not only correct but obviously so.

I will try to show in this review that the attraction of relativism and distaste for objectivism characteristic of legal scholars, and the dismissal of relativism and appeal of objectivism characteristic of mainstream moral philosophers, is in part a function of the differences in the types of evaluative enterprises undertaken by those respective disciplines. Legal scholars are likely to find both the attack on objectivism and the defense of relativism congenial to the peculiar array of professionalism-based needs, interests, and "economies" that distinguish that profession. Philosophers are in the opposite camp, again, for reasons that stem directly from their professional economies.

\section{Objectivism, Authoritarianism, and Legal Value}

Smith's core objection to objective moral and aesthetic evaluative reasoning is that its purported objectivity masks the interests and projects upon which value is inevitably contingent. When an evaluative judgment becomes authoritative-becomes accepted by the general community as true-the authority, including the political authority of the holder of those interests and projects on which the value is contingent, becomes further entrenched. When the contingency of the claimed value is hidden, the "value" becomes perceived as being in the world or in the object valued, rather than in the interrelationship between the economy of the evaluator and the functions and usefulness of the thing valued. The world becomes perceived as being a particular way-as containing an object, belief, practice, or tradition that simply has a particular value-and consequently all the more unchangeable. The political power behind moral or aesthetic authority becomes reified without its true nature having been acknowledged, much less open to challenge. ${ }^{15}$

There is no doubt that objectivist forms of evaluative reasoning in a wide range of disciplines are authoritarian in precisely the way that Smith describes. Smith's examples come from the tradition of moral and aesthetic philosophy, and they are well-chosen: Traditional moral philosophers' and aestheticians' claims of moral truth, based on presumably shared "intuitions," or linguistic conventions, or unassailable first principles, or man's inner nature, can without doubt be profitably reinterpreted as

15. Pp. 54-85. 
based on the philosopher's (or the group of which the philosopher is a member) needs, interests, purposes, or projects. But it is not clear that Smith's conclusion follows: that objectivism itself, rather than the examples of it that Smith presents, is inevitably authoritarian. In the next three subsections I will explore the merits of Smith's critique of objectivism in the somewhat different context of legal studies. First, I will look at the occurrence of objectivist evaluative practices in legal arguments that are offensive in just the way Smith suggests. In the second subsection, I will argue, against Smith, that objectivism, at least in legal discourse, is not necessarily authoritarian but can be put to decidedly anti-authoritarian ends. In the third subsection, I will then try to explain the distinctively subordinate, or "suspect," status of objectivist theories of value in legal theory, scholarship, and pedagogy.

\section{A. Objectivism and Legal Reasoning}

Although, as I will argue below, relativism is the dominant conception of value in legal theory, objectivist evaluative practices do appear in legal practice, and they are often dangerous in precisely the way Smith describes. Perhaps the most obvious legal example of objectivist evaluative practices masking the interests of the groups on which value is contingent is that peculiar form of evaluative behavior that pervades both the practicing and scholarly legal profession known as "Constitution worship." 16 It is indicative of how pervasive this evaluative practice is, that at least some who openly call it that-who recognize it as such-also openly practice it. ${ }^{17}$ The Constitution is widely regarded in the legal culture, and to a lesser degree by the general culture, as having objective value of an almost unassailable degree-that which is politically good is simply equated with that which is constitutional, and vice versa. The Constitution thus becomes all the more "authoritative"-not only in the normative sense but politically as well. Its mandates become increasingly unassailable, as it becomes increasingly identified in the popular and legal mind with objective good. ${ }^{18}$

It is always important, against this quasi-religious background, to illustrate simply the humanness of the constitutional project. The Constitution is a historical document, enacted to further particular and rather easily identifed interests-some of them political, even moral, even, perhaps, exalted, but most of them economic. Its "value" at the time of its enactment was quite obviously contingent on its usefulness to the interests, projects, and purposes of those whom it was designed to serve. Furthermore, the

16. See, e.g., S. Levinson, Constitumional Farth (1988) (providing full discussion of sacrosanct approach to the Constitution).

17. Id.

18. I have discussed this at length in West, The Authoritarian Impulse in Constitutional Law, 42 Miami L. Rev. 531 (1988). 
continuing value of the Constitution today is also surely contingent in precisely the sense meant by Smith. Thus, the "value" of the Constitution cannot be found in the document or its mandates. There are, of course, many persons who are well-served by the Constitution: politically active persons both in the mainstream and on the margin have an interest in the First Amendment; criminal defendants and potential criminal defendants have an interest in the various provisions of the Bill of Rights; the propertied class has an interest in the takings clause, the contracts clause, and the due process clause; state, Federal and local officials have an interest in the constitutional scheme of separation of powers; persons who for various reasons need their "privacy" protected against state intervention have an interest in the embattled right to privacy; and so on. The Constitution is of no value, however, for those to whom the document is simply irrelevant or marginal. Although the point is rarely acknowledged in the canon of constitutional literature, there are again many such persons: Children, non-Americans, illegal aliens, and insulated religious groups such as the Amish, all live in communities that simply have little to do with the relationships between Federal, state, and individual authority established by the Constitution. Those communities may be horrendous-such that the absence of constitutionalism in their midst is and should be perceived to be an injustice-or they may be harmonious. But they unquestionably exist. And finally, the Constitution is of negative value for those persons whose interests are at odds with the mandates of constitutionalism. Again, to take only the most obvious example, the Constitution was not only of no objective value but was positively lethal to slaves, escaped slaves, and freed slaves up to the passage of the Civil War Amendments.

Thus, the purported objective value of the Constitution is entirely a function of the interests it serves or disserves. The consequences of losing sight of this seemingly obvious point are extremely serious. As we lose our grip on the contingency of the Constitution's value, we not only further entrench its mandates, making the document itself less changeable, but we further entrench the political as well as moral authority of those on whose interests the value of the document is contingent-the propertied, the politically active, the verbal and articulate-and further subordinate and disenfranchise those whose interests are not. As we increasingly view the Constitution as objectively good, we increasingly view the needs and interests it serves as the deepest, or the truest, or the most enduring, or the most profound, or, as Smith could predict, the most truly human needs and interests-the need for privacy, the interest in unfettered political speech, the need for the security of property. Correlatively, we come to view the needs and interests it ignores or disserves as "merely" political, occasional, deviant, or superficial-the need for shelter, bodily integrity, safe intimacy. The ultimate consequence, of course, is that the political authority-the social as well as legal power-and as the normative au- 
thority of those whose interests are so served is all the more unassailable as it becomes less visible.

Of course, the contingency of the value of the Constitution on a set of human needs, projects, and interests is not itself a bad thing. Indeed it would be the worst of all worlds if the Constitution were utterly unhinged from the needs, and interests it purports to serve. It is the hidden contingency of its value which leads to the dangers described above. Once the contingency of its value is revealed, however, that relationship can become a progressive rather than regressive force: The Constitution should be of use to the interests, needs and projects of as many persons as possible, including those whom it presently disserves. If and when we change our communal sense of what interests and needs are worthy, we should be able to change the Constitution as well, so that those interests and needs are protected. What retards this process of political and constitutional reform on a superficial level is the dominant understanding of the Constitution as an unchanging legal and moral document, rather than as a plastic political document which can and should be responsive to political interests. What retards the process at a deeper level, however, is the understanding of the Constitution as possessing objective value in its own right-of defining, rather than being constituted by, the interests and needs and projects of objective moral worth. ${ }^{19}$

Thus, the sort of objectivist evaluative reasoning Smith is attacking is by no means a strawperson, in law no less than in literary theory or moral philosophy. The purported objective value of the literary canon to the critical literary establishment, the claimed or assumed objective accuracy of our moral intuitions and linguistic conventions for traditional moral and aesthetic philosophers, and the passionately embraced objective value of constitutionalism and legalism for lawyers does indeed mask the interests on which those values are in fact contingent, and the consequence in each case is indeed severe. Furthermore, a proper understanding of the contingency of the values being asserted in all of these disciplines would help us assess why we value what we value, and perhaps would allow us to broaden our evaluative practices so as to include the heretofore ex-

19. The "Rule of Law" serves the same function in legal philosophy as the Constitution serves in constitutional theory. The Rule of Law is widely regarded by the vast majority of legal scholars and practitioners as having objective value. See, e.g., Scalia, The Rule of Law as a Law of Rules, $56 \mathrm{U}$. CHr. L. REv. 1175 (1989). The consequence of the acceptance of this view tracks the consequence of the acceptance of the objective value of constitutionalism shown above: The contingency of the value of the Rule of Law on one set of interests and projects is hidden, thus further entrenching the political as well as normative power of the persons whose interests are thereby served. It does not, of course, follow from any of this that either the Constitution or the Rule of Law is a bad thing that should be dispensed with. What does follow, critically, is that the masking of the contingency of its value on particular interests has political consequences, and what follows normatively is that acknowledging and understanding the contingency of its value could increase its value, in relativist terms, by increasing its responsiveness to the interests and projects of a greater number of persons. 
cluded "economies" of excluded, silenced, or otherwise subordinated voices and interests.

\section{B. Objectivism and Authoritarianism in Legal Discourse}

It is not clear, however, whether authoritarianism is a necessary consequence or an inevitable component of objective evaluative reasoning. It is certainly possible to understand the development of the objectivist evaluative tradition as being profoundly anti-authoritarian, in law as elsewhere. Objectivism, so understood, is an attempt to highlight rather than to mask the political authority behind the official or dominant understandings of the good, by identifying the true or real good with that which is "objectively good"-external to the desires and whim of the dominant political powers. The good then operates as a critical check on the authority of the empowered-by virtue of its objectivity, the good, whether or not attainable or knowable, highlights by contrast the contingency of the values asserted by those in power on their interests and political status. Objective evaluative reasoning may be one of the strongest weapons we have against the very sorts of entrenched normative and political power of which Smith complains.

This virtue of objectivism may, as legions of postmodern critics of objectivity now assert, be ephemeral. It may be that the objectivist moral critic, once he attains any degree of credibility whatsoever, becomes the authority he initially set out to expose. At the extreme, it may even be the case that the articulation of any claim of objective evaluation leaves the critic in the same position as the authority being criticized: an "authority" on the nature of the good-political, cultural or otherwise-whose power is masked by the objective form of the evaluative utterance, even if that utterance is intended as itself critical of official or dominant power. But this is a historical question, not a philosophical one. We should look to the practice of objectivist evaluative inquiry, not its asserted nature, to determine whether a non-authoritarian or anti-authoritarian type of objectivism is now or has ever been possible.

At least with respect to objectivist discourse in law, I would assert a claim that is far more tentative than Smith's: My own sense is that objective evaluative discourse in law is always in danger of becoming authoritarian, but is not necessarily so, and that the distinction is tremendously important. Let me give two examples drawn from constitutional discourse, each of which exemplifies a very different kind of objective evaluative reasoning, where in each case the evaluative reasoning at least seems to be profoundly anti-authoritarian.

First, a critic or evaluator might define the ideal toward which a practice or culture ought to strive as necessarily distinct from, or opposed to, any authoritative pronouncement of the good, whether official or unoffi- 
cial, social or political. This definition would by all means include whatever power or authority is embodied in her own pronouncements. We might, in the constitutional realm, define the "constitutional ideal" as that ideal form of government toward which our actual constitutional practices ought to strive, including both the practice of making authoritative pronouncements regarding the meaning of the constitution and the practice of making critical pronouncements regarding the wisdom or virtue of these authoritative interpretations. The ideal constitutional principle then operates as a point of critical reference against which the product of authority in the constitutional realm can be judged.

This distinction between constitutional practices, authoritative (because final) Supreme Gourt interpretations, and critical interpretations on the one hand, and the ideal Constitution as a guiding critical point of reference on the other, is at least occasionally embodied (I believe) in the constitutional jurisprudence of Lawrence Tribe. The distinction is given its clearest articulation in Tribe's preface to his treatise, American Constitutional Law:

I do not regard the rulings of the Supreme Court as synonymous with constitutional truth. . . . [T]he Courts that held slaves to be non-persons, separate to be equal, and pregnancy to be non sexrelated can hardly be deemed either final or infallible. Such passing finality as judicial pronouncements possess is an essential compromise between constitutional order and chaos: the Constitution is an intentionally incomplete, often deliberately indeterminate structure for the participatory evolution of political ideals and governmental practices. This process cannot be the special province of any single entity. Thus my central topic is the Constitution itself, not the Supreme Court as an institution. ... [T] he ... crucial question for me is whether the judgment itself was right or wrong as an element in the living development of constitutional justice. ${ }^{20}$

It may not, of course, be possible to think of the ideal Constitution, or to use Tribe's phrase the "Constitution itself," as having any ascertainable content or meaning apart from some institutional forum in which the meaning of the document is ascertained. But we should not beg the quesion by simply assuming that it is impossible to do so. To determine whether this sort of objectivist moral reasoning, or in Tribe's case objectivist moral-constitutional reasoning, is covertly authoritarian, masking Tribe's own interests or projects, requires a close reading of the substance of his writings; it cannot be deduced from the form of his writings. ${ }^{21}$

20. L. Tribe, American Constitutional Law vii-viii (1988).

21. Thus, I do not mean to suggest that Tribe's writings are consistently idealist or objectivist, or that he even intends them to be; only that at least this prefatory comment suggests an idealistobjectivist aspiration or direction. 
To assume the viability of the concept of an ideal Constitution, and its workability as a critical guide against which constitutional practices (including the practice of criticizing "authoritative" constitutional pronouncements) can be judged, is to take a particular position regarding the nature of the Constitution as well as the possibility of objectivist evaluative reasoning. It is to see in the Constitution the possibility of a set of interpretive practices which are overtly normative and idealistic, rather than a document inextricably bound by its historical meanings and determinants. The viability of an idealist account of the Constitution as a matter of constitutional interpretation is beyond the scope of this essay, but it is worth noting that such an account is clearly possible. It is not wildly at odds with at least some of our present constitutional practices. It is true to the history of some of the noblest moments of constitutional decisionmaking. ${ }^{22}$ The point here, however, is a more limited one: We should not reject out of hand the viability of an ideal Constitution, whose meaning is distinctly different from all authoritative pronouncements of its meaning, because such a form of reasoning is itself necessarily covertly authoritarian. Particular instances or practitioners of ideal constitutional evaluative discourse may indeed be covertly authoritarian; Mark Tushnet's critique of Tribe's work suggests that Tribe's work may instantiate the authoritarian tendencies of objectivist discourse. ${ }^{23}$ But to prove or disprove the point, one clearly must look at the work; the "authoritarian tilt" cannot be inferred from the form of the discourse alone.

Second, it may be possible to formulate an ideal conception of human nature which does not prioritize or valorize, or normalize one's own attributes, interests, or needs, and to use such a conception as a basis against which to evaluate particular cultural practices, beliefs, traditions, and commitments. This form of objectivist moral reasoning may also be motivated by a strong anti-authoritarian impulse, Smith's examples to the contrary notwithstanding. The articulation of a theory of the good premised on a general description of a shared human nature is potentially both inclusive in its scope-all persons are entitled to whatever one person is entitled to-and anti-hierarchical-no class or subgroup's subordination can be justified by reference to naturalistic claims of the class' or subgroup's inherent or intrinsic difference or inferiority. John Stuart Mill's "ideal utilitarianism" clearly aimed toward such a project: Particular individual or cultural preferences notwithstanding, human nature is such that certain practices, such as a stimulating intellectual life and a rich and rewarding social and political life, tend toward the greatest happiness while other social practices, such as extreme material deprivation, isola-

22. I present this argument in more detail in West, Progressite and Conservative Constilutionalism, 88 Mich. L. Rev. 641 (1990).

23. Tushnet, Book Review, 21 Harv. C.R.-C.L. L. Rev. 285 (1986). 
tion, or intellectual deprivation, tend toward the greatest misery. This tendency is true of all persons, not just an aristocratic subgroup. Some of the early progressive American pragmatists similarly aimed to construct an ideal toward which practices ought be aimed, based on an evolving conception of human nature, and hence an evolving account of the good. ${ }^{24}$ Again, it is surely possible that any particular attempt to construct an ideal based on human nature fails, and that it fails in the way detailed by Smith: that it describes not human nature, but the "nature" of a particular individual, class, gender, society, or subcommunity. But that there are or may be failed attempts does not imply that the project is intrinsically undoable. It only indicates what should be obvious at any rate, and that is that the project is very difficult.

This Millian form of objectivism-moral reasoning grounded in an ideal account of the good, in turn premised on a general description of human nature-also has a correlate in constitutional reasoning. Many of the First Amendment dissents from the Holmes and Brandeis era, as well as the individual liberty cases of the Warren and Burger Courts, are premised on the assumption that the liberty that the First and Fourteenth Amendments protect must be the liberty to lead a good life. The nature of the good life is to be determined not by majoritarian preference or fiat, but by reference to an evolving account of the nature of the individual and the requisites of a full and meaningfully free life. Similarly, Professor Michelman's powerful arguments in the 1970's that the Constitution accords some degree of protection for welfare rights of minimal sustenance and shelter rested on Millian ideal utilitarian reasoning that the Constitution must promote the good life, and must therefore protect basic human needs. ${ }^{25}$

This type of reasoning, of course, is always in danger of becoming authoritarian in the way feared by Smith: certainly the Court, and arguably professional critics such as Michelman, may be imposing their own interests, needs, projects, etc., onto a purportedly idealized or general account of human nature and human needs. But again, that such a danger exists does not imply that such attempts must always fail. It may be that there are basic human needs which should be met, and human potentialities which ought be furthered, and human interests which should be satisfied, if any human being is to live a good life. It may also be that it is extremely difficult to specify what those needs, interests, and potentialities might be without imposing to some degree one's own-or those of one's gender, class, or culture-more particular needs, interests, or potentiali-

24. I discuss this ideal in detail in West, Liberalism Rediscovered: A Pragnatic Definition of the Liberal Vision, 46 U. PITT. L. REv. 673 (1985).

25. Michelman, Welfare Rights in a Constitutional Democracy, 1979 WASH. U.L.Q. 659 (1979); Michelman, The Supreme Court, 1968 Tern-Foreword: On Protecting the Poor Through the Fourteenth Amendment, 83 HARv. L. REv. 7 (1969). 
ties, and it may well be that the gender, class, race, or culture thereby prioritized is the dominant one. But it is not inevitably so, in the constitutional literature or in any other discipline. We should not infer that the objectivist project is wrongheaded because particular attempts to carry it to fruition often fail.

\section{G. Anti-Objectivism and Legal Economies}

Whatever the merits of particular objectivist evaluative practices, though, objectivism itself, within the legal academy, is widely identified with authoritarianism, hidden bias, and the reification of dominant interests. Anti-objectivism is absolutely mainstream doctrine in legal scholarship and traditional legal criticism. The hidden authoritarianism of claims to legal or moral objectivity in legal reasoning is presently a tenet of faith held not only by left wing critics, and certainly not only by the critical legal studies movement, but by legal scholars across the political spectrum. Furthermore, this skepticism toward objectivist reasoning holds in spite of, or more accurately alongside of, the near-routine invocation of "objectivity" as the justification for the almost blind faith of both the academy and the profession in constitutionalism discussed above. ${ }^{26}$ Thus, and somewhat paradoxically, in spite of its use of objectivist reasoning as a means of establishing its own foundations, and arguably as a means of reifying its own interests, legal academic thought has been almost univocally hostile to the idea or ideal of objectivist moral thought, and for the reasons put forward by Smith: Objectivism is typically perceived by legal scholars as a mask for dominant interests. Legal scholars as a group are profoundly skeptical of claims to objective moral truth or the objective good.

More specifically, anti-objectivism presently dominates the classroom, legal scholarship, and legal theory. To start with the classroom: attacks on purported objectivity, both in legal reasoning and in the moral reasoning that legal reasoning inevitably incorporates, are unquestionably the bread and butter of legal pedagogy. At least since the time of the legal realists, the substance of a typical law school class is the demonstration of the contingency of the value of a legal rule, in precisely the sense meant by Smith: demonstration of the way in which the value of a legal rule or institution is contingent on particular interests being served or needs being met. Indeed, the "bottom line" message of the typical class, course, or legal curriculum is the absence of legal or moral absolutes: the depen-

26. Critical legal scholars have written extensively on the apparently simultaneous commitment of mainstream legal scholars to objectivist and subjectivist theories of value, and the contradictions in liberal legalism to which those incompatible commitments Iead. See R. UNGER, KNOwLEDGE AND Politics 29-59 (1975). For a review of the critical literature, see M. Kelman, A Guide to CRITICAL LEGAL STUdIES (1987). I am making the far more limited point that mainstream theorists often, and perhaps typically, embrace an objectivist account of value for purposes of justifying fundamental commitments to the Constitution or the Rule of Law, and a subjectivist or relativist account of value for purposes of criticizing or reconstructing other legal and adjudicatory decisions. 
dency of legal reasoning on particular facts and circumstances, and the relevance of history and experience to the value of a legal rule, and therefore to the establishment of a legal truth and principle.

The same is true of legal scholarship. The substance of most law review articles is an elaborate demonstration of non-objectivity, or the contingency of legal value and legal truth on identifiable interests. This may have been novel during the heyday of legal realism, but it is no longer: Our three major scholarly traditions-the critical legal studies movement on the left, the law and economics movement on the right, and mainstream, pragmatic legal instrumentalism in the middle-may have vastly different politics and moral commitments, but they are uniformly united in their insistence on the contingency of legal value, the contingency of the truth of legal propositions on the experiences from which the law emerges, and the contingency of their value on the interests they purport to serve.

Furthermore, jurisprudential and philosophical attacks on "objectivity," "formalism," or "neutrality" recur with amazing frequency in the history of American legal theory. Attacks on objectivism within legal theory are sometimes critiques of the idea or ideal of objectivity itself, and are sometimes more pointed demonstrations that particular claims of objectivity are false. These are very different projects, and although they are frequently blurred, their premises are more in tension with than supportive of each other. Demonstrations of class, racial, or gender bias behind particular claims of objectivity often are premised on a passionate commitment to true objectivity, and get their moral force by virtue of that commitment, while demonstrations of the emptiness of the ideal of objectivity itself undercut any claims of true objectivity. But both sorts of attacks recur, often in tandem, throughout legal scholarship, and from critics and legal scholars who span the political spectrum. Such attacks may be the most constant, even the unifying, theme in American legal theory-at least American legal theory of the twentieth century.

In modern times, attacks on objectivity-whether they be attacks on the idea or ideal of objectivity itself, or attacks on particular claims of objectivity-are almost always motivated by a desire to expose the hidden authoritarianism behind claims to objectivity. This appears to be the case regardless of the political orientation of the critic. Four out of many possible examples from the last decade substantiate my point. Paul Brest's leftliberal critique of the ideal of objectivity in judging, appropriately titled Interpretation and Interest ${ }^{27}$ is in large part a reminder of the class, gender, and racial composition of the judiciary, and hence the likely content of whatever "objective" interpretation of law or morality such a group is most likely to render. John Ely's moderate-conservative critique of the jurisprudence of "objective" individual liberties and rights is simi-

27. Brest, Interpretation and Interest, 34 Stan. L. Rev. 765 (1982). 
larly informed by an observation of the homogeneity of the adjudicatory class and their preferences for rights that complement the life of the mind over other styles of living. ${ }^{28}$ Robert Bork's right-wing attack on noninterpretive jurisprudence is an attempt to expose the bias of an "elitist" liberal culture's pervasive influence on a similarly-tilted Federal judiciary. ${ }^{28}$ Lastly, Catharine MacKinnon's attack on the false objectivity of liberal legalism is aimed at exposing its gendered, hierarchic, masculinist content. $^{30}$ In all of these cases, objectivity-either the idea of it, or its purported realization in the works of particular legalists or judges-is unveiled as the mask of hierarchic domination of one group by others: either the privileged over the deprived; the learned over the unlearned; the elite over the masses; or men over women. What all four of these critiques share is that it is not only the hierarchic domination of one group by others that is found offensive, but more importantly, the form of that domination: the ability of the dominating group to hide its particular interests, needs, or projects in false claims of "objectivity," and thereby to transform the reality of its own power into a description-and a widely accepted one-of external reality. ${ }^{31}$

Thus, objectivism, no matter how orthodox in moral philosophy or aesthetic theory, is by no means dominant in the legal academy. Indeed, antiobjectivism (as well as relativism, as I will discuss in the next section) is far closer to legal orthodoxy than is objectivism. This holds true in spite of the legal profession's simultaneous commitment, often in the name of some form of "objectivity," to both constitutionalism and the Rule of Law, and in spite of the existence of objectivist forms of legal and moral reasoning that at least hold out the promise of anti-authoritarian critical analysis. Why might this be? Why should anti-objectivism emerge as the orthodoxy of the legal academy at the same time it remains, at.least according to Smith, a dissident tradition in philosophy and aesthetics?

There are undoubtedly many reasons. One reason, though, may be that objectivism serves a distinctive function in legal practice, which makes its authoritarian danger more pronounced, thus triggering a widespread skeptical response from legal scholars. Objectivist moral/legal discourse, like any form of moral discourse, may be put forward in two very different sorts of contexts. First, objectivism may constitute a form of critical discourse. A moral critic of the political, legal, or social action taken by another might criticize that action on objectivist sorts of grounds; the act is at odds with what, morally, is objectively required. Second, objectivism

28. J. Ely, Democracy and Distrust (1980).

29. R. BORK, The TeMpting OF AMerica (1989).

30. C. Mackinnon, Toward a Feminist Theory of the State (1989).

31. Although this critique is generally identified with the left, the same logic animates Robert Bork's attack on left-liberal constitutional law professors' departure from originalist understandings of the Constitution. Sep R. Bork, supra note 29, at 187-221. 
may constitute a form of justificatory discourse. A political or legal actor (as opposed to critic) may put forward an objectivist moral account of why he or she followed one course of action instead of another. Objectivism, in other words, like any other moral theory, may be used either by an outside critic to criticize action, or by the actor himself to justify action.

The danger that objectivism is being used to mask interests is obviously present in either case. Nevertheless, the danger that objectivist claims are being made in a manner that reifies and thus reinforces dominant interests is far more pronounced, more obvious, and perhaps even more often realized when objectivism is used by the actor himself, rather than the critic, for the simple reason that the consequences of the false reification of private interest into objective reality are made immediately apparent by the act itself. If objectivism does indeed bolster and strengthen the interests and power of the dominant in the way feared by Smith, then it will do so much more visibly when it is used to justify the actions of the strong than when it is used to criticize those acts. The act itself will be, presumably, an act of domination, and will demonstrate the subordinating effects of the reification on which its justification is premised.

If this is right, then it is not so surprising that objectivism is met with such suspicion in legal theory. Although there are important counterexamples, objectivism appears in legal writings overwhelmingly in the context of justificatory rather than critical moral discourse. Objectivism, one might say, is the bread and butter of a judicial opinion, the paradigm of justificatory moral reasoning. Indeed, objectivism is as central to adjudication as the exposure of false objectivity of legal opinions is to the law school classroom and law review article. At some level, the judicial decision charts a path for itself by describing either a general principle or a general description of the human good, based on an account of human nature, toward which particular laws or precedents ought be presumed to aim and against which ambiguities in rules can be resolved.

Any such "objectivist" opinion which falsely reifies one set of interests in the name of "human nature" does so not in the abstract, or in the name of criticism or scholarship, but while at the same time actively and openly exercising power over a disfavored group. The subordinating effects of the false reification, as a consequence, will be vivid, not subtle. Furthermore, this is surely as true of the opinions written by great judges who espouse or espoused realist critiques of objectivism in their non-judicial writings, as of judges who openly espouse some sort of objectivist philosophical perspective.

Examples of the false reification of the interests, needs, or as Smith would put it, "economies," of particular subgroups in the name of a general account of the good or of human nature in judicial decision-making are not hard to find. Some notorious cases, of course, are nineteenth century race cases justifying the institution of slavery or the separate but 
equal doctrine, or early twentieth century sex cases justifying differential treatment of women. From more modern times, the reasonable person doctrine in tort law is vulnerable to the complaint that it reifies the interests of some groups while subordinating others, as are self-defense doctrines in criminal law premised upon "general" understandings of the abilities and inclinations of victims of violence, and the contexts in which violence occurs. Perhaps the most vivid example, however, of the authoritarian danger always present in objectivist judicial discourse, is Holmes' opinion in Buck v. Bell, ${ }^{32}$ justifying, in the name of an objective view of the human good, human potential, and human nature, the involuntary sterilization of "imbeciles." Without a scintilla of subtlety, Holmes falsely reified in that decision one set of interests over another, deeming them the deepest interests of the "human race," and falsely asserted as objective a delineation between the fit and the unfit. That delineation, of course, and the "values" it purported to bolster, served, at best, not "human nature," but the cramped and misconceived interests or economies of the "State of Virginia."

At least since the time of the legal realists, the legal academy has been in the business of criticizing judicial opinions, and the most compelling ground of criticism has often been the false objectivity of those decisions. The professional interest in anti-objectivism, however, goes even deeper: Practicing lawyers, as well as legal scholars, are trained to extend, modify, overrule, or limit rules. They learn to do so for the most part by identifying the contingency of their purportedly absolute value-to discover, to use Llewelyn's phrase, the reason behind the rule, so as to insure that the rule not extend beyond its reason. Given the professional need to extend, manipulate, transform, or limit rules, it is not surprising that antiobjectivism has emerged not as a dissident conception of legal reasoning, but as orthodoxy in the legal academy, even while remaining marginal in the discipline of moral philosophy. It suits well the economy of the legal academy to be skeptical of the objective value, certainty, or truth of the legal rules which constitute both its objects of criticism and its tools.

\section{Relativism, Quietism, AND the Responsible Exercise of POWER}

Value, Smith argues, is always contingent; what it is contingent upon is the "economy" of the persons doing the evaluating. Thus, the aesthetic value of a piece of literature, the moral value of a cultural practice, the truth value of a proposition, cannot be found in the literature, the practice, or in any external reality or absolute set of evaluative truths. The value is entirely dependent upon the usefulness of the prose, practice, or 
proposition to the community, individual, or species with which the valued thing interacts. Usefulness in turn depends upon a complex personal, social, or species "economy"; economy, in Smith's analysis, is defined broadly so as to include both quantifiable and non-quantifiable interests, purposes, desires, projects, or (running a risk of circularity) whatever else tends to render something of value..$^{33}$

The latter half of Contingencies of Value is a defense of this sort of "economic relativism" against several "common objections," the most significant of which is the objection of "quietism." Economic relativism, argue its critics, is "quietistic" in its apparent acceptance, as given, of constituted tastes, preferences, desires, and projects, and the equation of a thing's value with its utility vis-à-vis those economies. But those tastes, preferences, and desires are themselves in need of evaluation-we can and do meaningfully speak of immoral preferences and tastes-thus suggesting the existence of some evaluative independent standard. Furthermore, those tastes, preferences, and economies are not pre-given or immalleable-they are themselves the product of social hierarchies, political actions, and various forms of decision-making that similarly are in need of evaluation and are subject to change on moral as well as utility grounds. The reduction of value to economy places those economies on which value is contingent beyond the sphere of evaluation.

Smith's response to the quietism objection is obscure, perhaps because she relies too heavily on the claim that the objection itself targets a strawperson, and that it assumes what should be the question-the existence of a standard of evaluation independent of the interests, projects, and personal and social economies under evaluation. ${ }^{34}$ The problem with such a response, of course, is that it too is question-begging: It assumes the non-existence of such a standard. The only way to resolve the resulting impasse, I suspect, is pragmatically: by looking at what relativist theories of value, and particularly the relativist theory of value put forward by Smith, can $d o$. Is a relativism possible that does not dissolve into a quietistic acceptance of our preferences, tastes, and projects? And if so, is it the relativism defended by Smith? In the first subsection below I will argue that Smith's version of relativism is indeed "quietistic," although relativism itself need not be. In the second subsection I will explore why a particularly quietistic form of relativism dominates legal-academic discourse.

\section{A. Economic Relativism and Quietism}

The economic relativism defended by Smith does seem to be quietistic, her protestations notwithstanding. We can see this both in her own treatment of the issue and, more importantly, in the quietistic role economic

33. Pp. 30-54, 54-85.

34. Pp. 156-66. 
relativism plays in our justificatory moral practices in legal discourse. First, at no point in Smith's treatment of the issue are the desires and preferences upon which value is contingent themselves put into question, nor is it shown how such an inquiry could proceed, given a relativistic framework. But the danger of quietism is most strongly evidenced, perhaps, in her dismissal of the need for critical theory, and its attendant conception of false consciousness.

Both the possibility and the need for critical theory, Smith seems to acknowledge, are inconsistent with the economic relativism being defended. What we should therefore do, she insists, is abandon not economic relativism, but critical theory itself. Critical theory is not only inconsistent with relativism, but because of that inconsistency, it commits the authoritarian sins of objectivism: It rests on a purportedly objective but invariably partial account of "true" human nature, human potential, and human needs, against which the socially constructed needs of the subordinated are found wanting. Thus, Smith argues:

Like others . . . who continue to find Marxist economics the most viable comprehensive grounding of oppositional political action, . . . [Charles] Levin writes: "And so we have the autonomous subject, making free choices, independently. This is an indispensable idea, so fundamental that if we do away with it completely, we explode any recognizable version of 'emancipation' . . and implicitly, we abandon the possibility of critical theory." What is evidently not to be thought of here is that perhaps "the possibility of critical theory" must be abandoned: that is, that insofar as "critical theory" is understood as any analysis that strives and claims to expose ideology or false consciousness and thereby to reveal the true, underlying, actual workings of the present state of affairs or "system". . . , it is problematic in itself. It is most obviously problematic in that it presupposes an asymmetric epistemology and posits a sharply stratified and polarized collectivity with, on the one hand, those who already know the objective truth and, on the other, those so captivated by the system in question that they cannot recognize their own interests or desires, including what must be posited as their hidden, distorted, or perverted but still fundamental and ineradicable underlying desire for what the critical theorist sees as the necessarily desirable alternative to the present state of affairs: for example, a classless society, sexual equality, or human emancipation. Since the existence of this underlying desire is not self-evident, it must be posited as there in spite of all evidence to the contrary, and the critical theorist, in his effort to explain how we, the enlightened, know that they, the unenlightened, really do desire the radical transformations for which they seem disinclined to agitate, will always move, in strict accord with 
axiological logic, to the creation-by-invocation of just the necessary human universals. ${ }^{35}$

The dilemma facing the critical theorist is a very real one, as examples drawn from critical legal thought clearly show. Catharine MacKinnon's critical work, to take one modern example, compellingly illustrates the authoritarian danger in critical theory that Smith rightly fears. Professor MacKinnon's exposure of the expropriation of women's sexuality in patriarchal society crucially depends upon the critical claim that women's felt desires or preferences for heterosexuality, and their felt experience of those desires as on occasion non-coerced, are false: that they are the product of a social hierarchy that must itself be subjected to criticism, and therefore cannot constitute the basis against which such criticism should proceed. It is surely this aspect of her work which has sparked the most criticism and the most dissent, and for precisely the reasons Smith insists upon: The objectivist critical attack on felt preferences and desires rests upon an authoritarian pronouncement, express or implied, as to women's "true nature," which invariably simply prioritizes one possible way of being over others. Professor Wendy Brown's recent critical comments on Catharine MacKinnon's work The Nation are illustrative:

MacKinnon dismisses or ignores even the most obvious challenges to her argument: women whose lives appear at least as heavily marked by a gendered division of labor as by sexual objectification, same-sex sexual relations gendered in ways not easily reducible to polar inequality, or manifestations, however partial or paradoxical, of female sexual agency and pleasure. Nor does MacKinnon acknowledge the tremendous range in sexual construction and sexualities, a diversity evident even among women of one race, class and epoch, let alone across these variables. She simply ignores these things . . . . Any expression of women's differences, as well as any moments of power, pleasure and agency that call into question the total and systematic quality of gender subordination, must therefore be explained away as illusory, challenged as liberal, fainthearted or apologist, or denounced as collaborative with the regime, all of which MacKinnon does whenever she encounters a feminist argument or practice at odds with her account. ${ }^{36}$

Whatever the force of this critique, however, the example proves far too much. For whatever the difficulties in doing so, Professor MacKinnon is surely right to put into doubt women's presently felt desires, projects and preferences. An unsurprising, indeed common, response to conditions of oppression is precisely to come to desire the only choice one is given: If

35. Pp. 173-74.

36. Brown, Consciousness Razing, The Nation, Jan. 8/15, 1990, at 62-63. 
women's only choice-and hence no choice at all-is to relinquish control of their sexuality to men, then that is what many women will come to feel they desire. It is simply more efficient-to say nothing of safer-to do voluntarily, willingly, and at the extreme desirously, what one is being forced to do in any event, with or without one's acquiesence. Where the levers of oppression are as invisible, as relentless, and as pervasive as are the levers of patriarchal control, then one of the few ways to expose those levers is to throw into serious doubt the authenticity of the desires and preferences they produce. It is difficult, but surely not impossible, to accomplish this critical project without begging central questions and resorting to circular arguments. It is also a project we cannot avoid, if we are serious about exposing, to say nothing of ending, the patriarchal sources of power that control and expropriate women's sexual lives.

The logical problem, however, facing the critical theorist, of exposing the falsity of presently felt desires or preferences, pales in comparison to the ethical and practical problem facing the critical activist in doing something about it, as the feminist ambivalence over Professor MacKinnon's proposed anti-pornography legislation vividly shows. Critical theory faces only the objection that it rests on objectivist premises that in turn reify a set of interests in the name of a false reality. Critical practice, however, does more: It rests on objectivist premises that in turn reify a set of interests in the name of a false reality which will, quite immediately, serve to oppress whatever set of experiences or interests fall outside the idealized vision of nature upon which the proposed reform rests. The practical consequence, in other words, of putting into serious question the authenticity or falsity of felt preferences and desires, rather than viewing those preferences and desires as the baseline of our evaluative practices, may well be a form of oppression more dangerous than the sources of oppression the legislation is meant to address. The political actor as well as the critic worried about social hierarchy, finds herself on the horns of a dilemma which is profoundly ethical and practical, not just logical: She can either legislate in such a way that quietistically rests on the authority and givenness of presently constituted preferences-in spite of the contingency of those preferences on social processes which may themselves be hierarchic and offensive-or she can legislate in such a way that aggressively attacks the social structures that create those preferences-running the risk of authoritatively and oppressively running roughshod over the experiences and felt interests of the very subordinated whom she is trying to help.

It is not at all clear how this dilemma should be resolved, either abstractly or in particular cases. It is clear, though, that simply denying the existence of one of the horns of the dilemma-which is the apparent strategy of the economic relativist-is not a solution to the problem. ${ }^{37}$ The

37. At several points in her text, Smith notes her belief that the economic relativism she is defend- 
preferences and desires of all of us, but particularly those of us who, within various spheres of social life, are relatively disempowered, cannot be the basis of our evaluative practices. Those preferences and desires are themselves the product of social structures of which we must be critical. The personal and social economies on which Smith relies as the baseline of evaluative practices must themselves be the object, not the method, of evaluation.

The history of economic relativism within legal practice and theory also suggests that the objection of quietism is not, as Smith suggests, a delusion of misguided objectivists obsessed with a strawperson caricature. It is true that there is nothing intrinsically conservative about economic relativism with respect to our positive law: our preferences, desires, projects, and all other aspects of our personal and social economies may counsel the need for a great deal of legal reform. Our legal system, principles, rules, and precedents may fail to serve our interests for any number of reasons, and may certainly be modified so as to render them more useful. But there seems no doubt but that economic relativism is tremendously conservative with respect to societal structures-both those that do and those that do not implicate law itself - that generate those desires and preferences. The logic of the law and economics movement-the closest analogue in the legal culture to the economic relativism Smith is defending--leaves little doubt but that economic relativism, put into practice, will leave the preferences and desires upon which all value is contingent beyond evaluative discourse, and thus the social structures and systems which generate them beyond the purview of social criticism and change. ${ }^{38}$

However, the quietism that weakens the viability of the economic relativism Smith is defending does not seem an intrinsic feature of relativism; it seems, rather, an intrinsic feature of the normative economics with which Smith is intent on conjoining relativism. Non-quietistic but relativistic theories of value are certainly possible, just as are non-authoritarian but objective theories of value. Whether a relativist theory of value is or is not quietistic depends upon what the value is held to be relative to, or what it is contingent on. To give just a few examples: Relativism can and

\footnotetext{
ing is compatible with "other key aspects of . . Marxist and feminist theory." P. 174. More generally, she suggests that relativism is compatible with virtually any moral theory, including, presumably, Marxism and/or feminism, and that "no particular moral positions . . . follow from (relativism) at all." P. 161 (emphasis omitted). She does not explain, however, what "key aspects" of Marxism or feminism are compatible with relativism. Further, since the "key" concept of "false consciousness," with its attendant objectivist critique of the presently constituted subjective desires and preferences of the disempowered, is so clearly anathema to Smith's relativism, it is at least the case that Smith's relativism is incompatible with Marxism(s) or feminism(s) that rely upon it. It is not clear what is left of Marxist or feminist analysis once this key concept is abandoned. Unfortunately, Smith does not elaborate her suggestion that some version of critical theory or theories may be derived from her relativist premises.

38. For a full demonstration of the conservatism of the law and economics movement, see M. Kelman, A Guide to Critical Legal Studies 151-85 (1987).
} 
sometimes has meant nothing more than that moral questions must be resolved contextually - that there are no "categorical" imperatives. Value is always contingent on the particular human situation in which the agent finds himself or herself. There may be nothing much asserted here, beyond the rejection of the notion of the categorical, but nevertheless there is clearly nothing quietistic that follows from the claim that the value of something depends upon context. Second, "relativism" can and sometimes does mean only that value is contingent upon human practice and experience-whether something is or is not of value must be determined by examining our experience of what we are evaluating-rather than by deduction from absolute principles of moral truth. Again, while this may be too general to be helpful in resolving particular dilemmas, there is nevertheless nothing quietistic about it. And third, relativism can, and sometimes does, simply connote a very broad and idealistic consequentialism-whether something is of value might depend upon whether it is conducive to the greatest good or the greatest happiness of which we are potentially capable. This form of relativism undoubtedly gives rise to the sorts of essentialist objections that concern contemporary postmodernists-like some objectivist theories, it rests on essentialist portrayals of ideal happiness, or the ideal good-but again, there is nothing quietistic about it. None of these versions of "relativism" quietistically rests on the givenness of presently constituted interests, needs, or desires as the baseline of ethical criticism.

\section{B. Relativism and the Economies of Law}

In legal studies, economic relativism, with its attendant quietism, is without question the dominant theory of value. Most law professors and the vast majority of law students espouse some version of economic relativism. Correlatively, scholarly attacks on economic relativism-particularly critical demonstrations of its quietism in given areas of law, legal institutions, or lines of authority-within the legal academy are relatively rare and difficult, and they typically fail to persuade. Critical legal scholars, some feminists, and more recently civic republicans have revealed the quíetism, and the attendant conservative bias of the academy's commitment to relativism. Mark Kelman and Duncan Kennedy have shown how economic relativism bolsters conservative values in private law; ${ }^{39}$ Cass Sunstein and Frank Michelman have done the same in public law; ${ }^{40}$ Catharine MacKinnon has made similar demonstrations with respect to

39. Sic ad.; Kennedy, Distributive and Paternalist Motives in Contract and Tort Law, with Sprcal References to Compulsory Terms and Unequal Bargaining Pouter, 41 MD. L. Rev. 563 (1982).

40. Sre Michelman, Law's Republic, 97 Yale L.J. 1493 (1988); Sunstein, Bejond the Republiran Rruizal, 97 Yale L.J. 1539 (1988). 
patriarchal values in family law and criminal law. ${ }^{41}$ Judge Marvin Frankel has written critically of the relativism that dominates the bar, frustrating the quest for truth and justice, ${ }^{42}$ and David Luban has written persuasively of the emptiness of the "adversarial excuse" embraced by the legal profession to justify the advocacy of injustice and falsehood. ${ }^{43}$ These critical commentaries, however, are demonstrably marginal, and emanate from demonstrably marginal intellectual movements within the legal academy. The critical theory that dominates the critical legal studies movement, the communitarianism behind the revival of civic republicanism, the overtly political point of departure for feminist studies, and the ethical objectivism that underscores the critical work of David Luban (the only non-lawyer of the above group) -all are at odds with the relativism that dominates mainstream legal studies and practice, and hence at odds with mainstream legal studies and practice themselves. Thus, legal scholars are committed and trained anti-objectivists, remarkably sensitive (with only occasional lapses) to even the slightest possibility of authoritarian bias in purportedly objective analyses or evaluations but at the same time, almost blind (with only occasional exceptions) to the quietism that just as assuredly endangers the integrity of relativism as authoritarianism endangers objectivism.

Why should this be? Why is the quietism of relativism so much harder for the legal scholar to see than the authoritarianism of objectivism? There are many reasons, but one may be the centrality of adjudication-its processes, its method, its own internal evaluative practices-to both legal practice and legal studies. The need to adjudicate implies the need to find an "authoritative," and not just a correct answer to legal dilemmas. The judge must find an unquestionable foundation. As discussed in Section I, for some, and perhaps most judges, the unquestioned, authoritative foundation will be a commitment to an objective source, such as the Rule of Law or the Constitution. But for at least some judges, typically the better judges, and undoubtedly the judges most esteemed by legal scholars, objectivist reasoning is an unsatisfying adjudicative method for the reasons expounded by Smith.

The exceptional non- or anti-objectivist judge, however, although the legal scholar's hero, is in a very difficult bind. All judges-including nonobjectivists-must find "authority" for their legal decisions, including those for which the law itself is ambiguous. For non-objectivist judges, the unquestioned, authoritative foundation for such legal decisions can be found neither in the law itself, nor in objective moral reality. Despite the appearance of paradox, that authoritative foundation might be found in-

41. See C. MacKinnon, supra note 30.

42. M. Frankel, Partisan Justice (1980); Frankel, The Search for Truth: An Umpireal View, 123 U. Penn. L. Rev. 1031 (1975).

43. See D. Luban, Lawyers and Justice (1988). 
stead in relativism, but it can only be found in a relativism that is at root, and by necessity, quietistic. The interests, preferences, and "economies" of the interested parties must be taken as given if they are to be "authoritative." Thus, for relativism to fulfill its function-to be of "use" to the non-objectivist adjudicator-it must be "quietistic": It must quiet objections. Inquiry must end, the case must be decided, and-given interests, preferences, and desires-it must provide the endpoint. The antiobjectivist judge is in some sense committed to relativism. But the judge who considers himself or herself "bound by law" must also be committed to authoritativeness-the judicial answer must be decisive, must rest on an unquestioned foundation, must be "lawful" and "lawlike," must quiet objection. For the non-objectivist judge to avoid the scylla of authoritarianism in the hard case he must shun objectivism; but for his consequent relativism to avoid the charybdis of lawlessness, it must be quietistic. The quietism which to the moral philosopher and the critical theorist is relativism's most glaring flaw, to the relativist judge is its great virtue. The quietism of economic relativism perfectly fits the "economy" of the judicial decision in the hard case. Given the paradigmatic role of the nonobjectivist judicial decision to legal scholars-it is in some sense the quintessence of good legal reasoning-it is no wonder that it is so difficult for the legal scholar to see that the quietism of economic relativism may be part of the problem, rather than part of the solution. It runs against the grain of our economy.

\section{ConClusion}

Contingencies of Value does not deal directly with legal studies, with the value of law, or with the evaluative practices of lawyers, judges, or legal scholars. The contrast, however, between the evaluative practices of lawyers, judges, and legal scholars on the one hand, and aestheticians, literary critics, and moral philosophers on the other, is both stark and illuminating.

Within the legal academy, the economic relativism Smith defends is the dominant tradition, while the objectivism she attacks is the dissident voice. This may not be as anomolous, however, as it first appears. For the reasons discussed above, legal scholars most admire and emulate the nonobjectivist judge, particularly the non-objectivist judge who grapples honestly with the hard case. But even that judge must justify his or her decision. Within a liberal tradition committed to the governance of law, for judicial action to be justified it must be authorized -it must not rest on whim or caprice, but must rest on some agreed foundation. Where the governing law is clear and clearly democratic, such justifications are relatively straight forward. But in the so-called "hard case," where the governing law is ambiguous, legal action is notoriously hard to justify. This is 
often referred to as a central, if not the central, dilemma of liberal legalism.

Economic relativism rather strikingly provides a conception of value which relaxes the dilemma facing the non-objectivist judge, and hence the non-objectivist scholar who seeks to justify action where the law is unclear. The "authority," according to economic relativism, on which the decision ought rest is the social economy of the community served by the law. Social economy should provide the certainty-the authority-that law, when it is ambiguous, cannot. And, its apparent flaw-its quietistic acceptance of the social structures that influence if they do not produce those economies-is precisely what renders it "authoritative." Economic relativism thus solves the "economic" dilemma of liberal legalism faced by the non-objectivist judge: It provides an authoritative but nonauthoritarian resolution of legal ambiguity. From the perspective of the non-objectivist judge, and hence, derivatively, of the non-objectivist legal scholar-the "justificatory perspective"-economic relativism perfectly justifies the judicial decision made in the face of legal ambiguity.

From a critical perspective, however, this economic resolution of the dilemma posed by legal ambiguity is by no means satisfactory: It looks like an abdication of responsibility. The judge has some measure of power, which presumably ought to be put toward the end of justice. Satisfaction of the present interests, preferences, and projects of the relevant communities may indeed provide the best measure of justice, but they may very well not. Where they do not, the judge who abdicates to "interest" and economy, and the scholar who advocates that choice, is sacrificing justice for efficiency. The intuition remains that this is a sacrifice of value, that this is something the judge ought not do. The judge who does so-even if acting from the noble desire to minimize the danger that were he to act otherwise he would be using his power in such a way as to impose his own interests-is maximizing the risk of quietism. He is further entrenching the power of the social structures most instrumental in the production of those economies he satisfies. Those structures may be noble, fine, democratic, and for the good of all. But then again, they might not.

Is this something we should worry about? It is clearly not a danger that troubles most legal scholars: Legal scholars are attuned to-even obsessed with-the danger of excessive judicial power when that power is masked by objectivist rationalism, but almost deaf to the danger of unchecked social power to which judicial abdication-often in the name of relativism-can lead. I have suggested here that the need for authoritative guidance that constantly haunts the overwhelmingly justificatory flavor of legal studies may account for this choice. But there is another and simpler-more economic-explanation as well.

The simpler explanation is that we haven't focused on the problem. We 
presently do not have-and perhaps desperately need-theories of value aimed toward action rather than criticism. Our developed and competing moral traditions for the most part originated within fields of study concerned primarily with evaluative critical practices: How should we criticize acts of power, either personal, individual, or political? To what standard should various actions be held? My suggestion is that we need to focus more attention on how we answer the somewhat different question: How should we act? Within the legal context, this means that we need a conception of virtue that can guide legislative, judicial, and adversarial action that goes way beyond the ethical mandate to avoid corruption. How should someone with power use that power? What is the good toward which legal action should be aimed? How can a judge, and can a judge, be committed to social justice and the eradication of wrongful social hierarchy? Can he act on that commitment in a non-authoritarian way? These are obviously questions of political theory and jurisprudence, but they are also questions of ethics. From an ethical point of view, both authoritarianism and quietism are forms of amorality and irresponsibility: The difficulty of the adjudicatory task is to avoid both.

At present we are intrigued by two apparent resolutions of the dilemma, both of which, I think, represent false starts. First, we do not solve the difficulty by generating a perfect legal process that protects us against one or the other of the two horns of the dilemma. To summarize in a phrase a massive body of critical commentary, the irreducible ambiguity of the language of law insures that individuals-particular judges-not systems, will at least on occasion be empowered to act well or poorly. Secondly, we do not solve the difficulty by demonstrating that one or the other of the two horns of this dilemma does not in fact exist, or need not exist. The danger that objectivist moral reasoning can be a mask covering the authoritarian imposition of a view of life, of human nature, and hence of a set of dominant interests on subordinate groups is a very real one. But the other danger is also real, Smith's protestations and the relative blindness of the legal academy to it notwithstanding: Economic relativism is indeed quietistic, and often unjustly so, toward the very real imbalances of power and attendant cruelties that constitute our social life. Economic relativism lends certainty to legal decisions, but it often does so at the cost of social justice. Both dangers are real, and neither can be reduced to zero through legal process.

If it is possible to meet the challenge-to adjudicate in a way that fairly minimizes, if not avoids, the competing dangers of authoritarianism and quietism-it is possible because particular individuals possess and exhibit the requisite strengths of character. Thus, it is virtue, not legal process, and not moral philosophy, and not a commitment to either relativism, objectivism, or any other "theory of value," that makes possible good judging. It is of what that virtue might consist, and what those strengths of 
character might be, which constitutes the unaddressed agenda of this postrealist and post-critical era in legal scholarship. At a minimum, the judge (or lawyer) who performs well-who is responsive to both the authoritarian danger of objectivist thought and the quietist danger of relativism-has a heightened sensitivity to the plight of others-particularly the silenced, the outsider, and the subordinate. She also has a commitment to justice and the social good, and at the same time both a humility toward her own conception of what the good requires, and an acknowledgement and appreciation of the worthiness of competing accounts. But that is obviously only a minimum. We need far richer conceptions, or descriptions, of judicial and legal virtue if we are to further productively the inquiry that Smith has begun. The great accomplishment of the legal realist and critical legal studies movements in this century has been to demonstrate, against the persistence of formalist and processual claims to the contrary, the necessity of such a theory. The irreducible gaps in the law demonstrate the need for judicial action, and hence judicial virtue. After a century of realist and critical inquiry we now see the need to ask of what that virtue might consist. But we have only begun to formulate the relevant questions-how should a judge use her power; how should a lawyer use his? And we have not even begun to provide the answers. 